\title{
A Fire Zone Model Including the Cooling Effect of Sprinkler Spray on Smoke Layer
}

\author{
DONG YANG, RAN HUO, LONGHUA HU, SICHENG LI and YUANZHOU LI \\ State Key Laboratory of Fire Science \\ University of Science and Technology of China \\ Jinzhai Road 96, Hefei, Anhui, P.R. China, 230026 \\ Corresponding author: Tel: (86) 551 3601660; Fax: (86) 551 3601669; Email address: \\ huoran@ustc.edu.cn; hlh@ustc.edu.cn
}

\begin{abstract}
As sprinklers systems are widely adopted as fire fighting devices in buildings, it is necessary to develop quantitative models for investigation of the influence of sprinklers on fire development. A fire zone model which includes the cooling effect of sprinklers is developed. Heat transfer from the smoke layer to sprinkler water spray was considered as an additional heat loss term in energy balance equation. In the absence of a sprinkler, the predicted temperature of this model matched that of CFAST6.0, while when sprinkler effects were included, the model predicted the temperature profile of the smoke layer with good agreement with published experiments. This model was applied to a hypothetical compartment fire. Results showed that a higher heat release rate of fire led to a significant decrease in smoke temperature following sprinkler activation, while only a small decrease in smoke layer temperature is predicted when increasing sprinkler pressure from $0.05 \mathrm{MPa}$ to $0.1 \mathrm{MPa}$.
\end{abstract}

KEYWORDS: zone model, sprinkler, cooling effect, experiment validation, compartment fire

\section{NOMENCLATURE LISTING}

\begin{tabular}{|c|c|c|c|}
\hline$c_{p}$ & specific heat $(\mathrm{kJ} / \mathrm{kg} \cdot \mathrm{K})$ & $\dot{Q}_{r}$ & $\begin{array}{l}\text { radiative heat transferred from smoke } \\
\text { layer to wall boundaries and lower } \\
\text { layer }(\mathrm{kW})\end{array}$ \\
\hline$C_{d}$ & drag coefficient & $\dot{Q}_{f}$ & heat release rate of fire $(\mathrm{kW})$ \\
\hline$d$ & droplet diameter $(\mu \mathrm{m})$ & $t$ & time (s) \\
\hline$D$ & thickness of smoke layer (m) & $t_{f}$ & $\begin{array}{l}\text { reservation time of water droplet in } \\
\text { smoke layer (s) }\end{array}$ \\
\hline$d_{m}$ & median diameter of droplets $(\mu \mathrm{m})$ & $T_{e s}$ & $\begin{array}{l}\text { average temperature of smoke layer in } \\
\text { experiment }(\mathrm{K})\end{array}$ \\
\hline$d_{0}$ & minimum diameter of droplets $(\mu \mathrm{m})$ & $T(d)$ & $\begin{array}{l}\text { temperature of the droplet with } \\
\text { diameter } \mathrm{d}(\mathrm{K})\end{array}$ \\
\hline$d_{\infty}$ & maximum diameter of droplets $(\mu \mathrm{m})$ & $T(d)_{f}$ & $\begin{array}{l}\text { temperature of the droplet with } \\
\text { diameter d when it exits from smoke } \\
\text { layer }(\mathrm{K})\end{array}$ \\
\hline$g$ & acceleration of gravity $\left(\mathrm{m} / \mathrm{s}^{2}\right)$ & $T_{0}$ & initial temperature of water droplet (K) \\
\hline$h(d)$ & $\begin{array}{l}\text { Convective heat transfer coefficient of } \\
\text { the droplet with diameter } \mathrm{d}\left(\mathrm{kW} / \mathrm{m}^{2} \cdot \mathrm{K}\right)\end{array}$ & $u$ & $\begin{array}{l}\text { horizontal velocity of water droplet } \\
(\mathrm{m} / \mathrm{s})\end{array}$ \\
\hline$k$ & Thermal conductivity of air $(\mathrm{kW} / \mathrm{m} \cdot \mathrm{K})$ & $V_{s}$ & volume of upper layer $\left(\mathrm{m}^{3}\right)$ \\
\hline$m$ & mass of water droplet (kg) & $V_{w}$ & $\begin{array}{l}\text { volume discharge rate of water droplets } \\
(\mathrm{L} / \mathrm{s})\end{array}$ \\
\hline$\dot{m}_{p}$ & $\begin{array}{l}\text { mass accumulation rate flowing across } \\
\text { the layer interface }(\mathrm{kg} / \mathrm{s})\end{array}$ & $v$ & vertical velocity of droplets (m/s) \\
\hline$\dot{m}_{v}$ & mass flow rate through vent $(\mathrm{kg} / \mathrm{s})$ & $y(d)$ & $\begin{array}{l}\text { probability of the droplet with diameter } \\
d\end{array}$ \\
\hline$N(d)$ & number of droplets with diameter & $z$ & distance normal to ceiling (m) \\
\hline $\mathrm{Nu}$ & Nusselt number & Greek & \\
\hline$Q_{c}(d)$ & $\begin{array}{l}\text { The heat transferred to the droplet with } \\
\text { diameter } d \text { from smoke layer }(\mathrm{kW})\end{array}$ & $\rho$ & density $\left(\mathrm{kg} / \mathrm{m}^{3}\right)$ \\
\hline
\end{tabular}




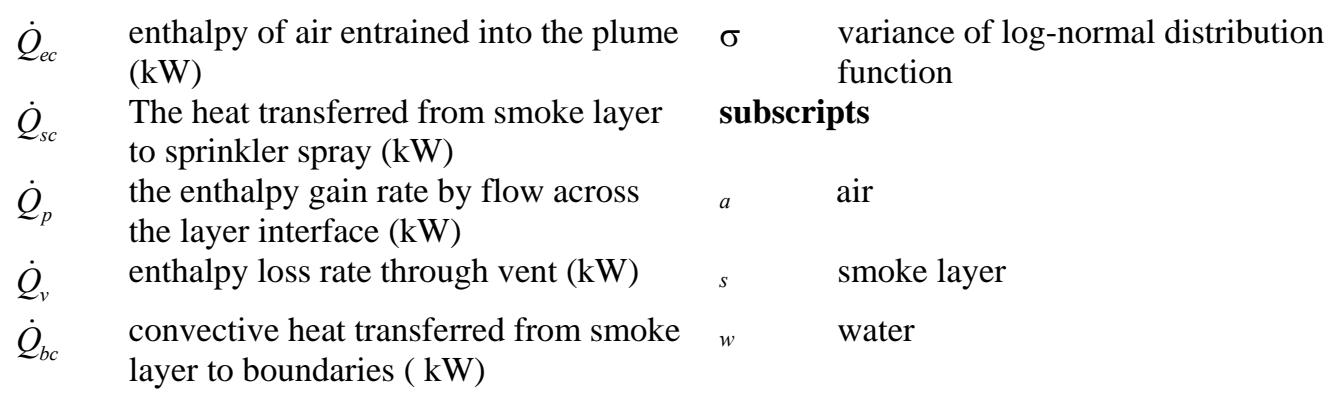

\section{INTRODUCTION}

The sprinkler is considered to be one of the most effective and reliable of all fire fighting tools. Quantitative studies of the sprinkler's influence and efficacy on the fire development is important. The effect of sprinklers is generally ascribed to two characteristics [1-2]: (1) reducing the heat release rate by directly suppressing the fire; (2) cooling of the hot smoke layer and thus reducing radiative heat transfer from smoke layer back to the fire. Zone modeling is one of the most widely used approaches for fire simulation. The two-layer zone model CFAST6 includes a model of fire suppression [3], but does not include the cooling effect of sprinklers on smoke layer. For this reason, it excludes the important effect of sprinklers delivering water droplets into the burning region of a fire. Cooper [4] studied the interaction of sprinkler spray on the hot smoke layer using the methodology of zone modelling. His study accounted for heat losses of the smoke layer due to water evaporation of sprinkler spray, but did not include losses due to convective heat transfer. On the basis of a zone model for a hot smoke layer, Novlzhilov [5] analyzed the critical water discharge rates required for flashover prevention. However, the assumption that the water droplets have uniform diameters is not in agreement with experimental conditions, and simplifications were made on the energy source terms in his study. Vaari [6] proposed a transient zone model for total flooding water mist fire suppression. This model was developed for predicting the suppression capability of water mists, and sprinklers were not included in his study. Morgan [7] developed a theoretical model for heat transfer from smoke layer to sprinkler spray. His work derives from the heat absorption by a single water droplet, from which he derived the total heat transferred to sprinkler spray from smoke layer. This model has been used in a number of subsequent studies [5, 8-10] and was improved by Chow and Fong [9]. The limitation in engineering application of these models may due to the fact that they depend on the temperature and thickness of smoke layer which vary during a fire scenario.

The objective of the present study is to develop a fire zone model which includes the effect of cooling the smoke layer by sprinkler spray. The heat transferred to the sprinkler spray from the smoke layer is included as a heat loss term in this model. In order to estimate the heat absorbed by the sprinkler spray accurately, a model which includes droplets size distribution is used. Since this fire zone model has accounted for the cooling effect of sprinklers on the hot smoke layer, if the water does not reach the fire, it does not predict the fire but rather the temperature conditions in the smoke layer. This zone model is of significance for fire safety design.

\section{HEAT TRANSFER FROM SMOKE LAYER TO SPRINKLER SPRAY}

A sprinkler's effects on fire development manifests itself in two ways: by suppressing the fire and cooling of the hot smoke layer. Fig.1 shows the two situations in which sprinkler affects fire development. Sprinklers have a direct effect on the fire when water droplets can reach the fire region, however, as is shown in Fig.1, the sprinkler may be located away from fire locus where the droplets only pass through the hot smoke layer. Direct fire suppression is achieved only in the former case. However, the cooling effect of sprinkler water on the hot smoke layer must be included in either of the two cases. The phenomena of cooling of smoke layer by sprinklers include regimes of convective heat transfer, radiative heat transfer as well as evaporative heat absorption. Only very fine droplets will be heated to their boiling temperatures when traversing through the hot layer, and both theoretical and experimental studies report that evaporative heat losses are small relative to convective heat transfer [11-13]. Therefore, only convective heat transferred from smoke layer to sprinkler droplets is included in this heat transfer model. 
Sprinkler sprays are composed of droplets ranging by over two orders of magnitude in diameter. The common distribution functions used to describe droplets are log-normal distribution and Rosin-Rammler distribution [14]. In this paper, log-normal distribution function is used:

$y(d)=\frac{1}{d \sigma(2 \pi)^{1 / 2}} \exp \frac{-\left[\ln \left(d / d_{m}\right)\right]^{2}}{2 \sigma^{2}}$

where $y(d)$ denotes the possibility of a droplet of diameter $d, \sigma$ is the variance of log-normal distribution function, $d_{m}$ is the median diameter of droplets, which is related to Webber number [15-16]

The number of droplets discharged with diameter $d$ per second can be taken as:

$N(d)=\frac{V_{w} \cdot y(d)}{\sum_{d=d_{0}}^{d=d_{\infty}} \frac{y(d)}{6} \cdot \pi \cdot d^{3}}$

where $V_{w}$ is the volume discharge rate of water droplets.

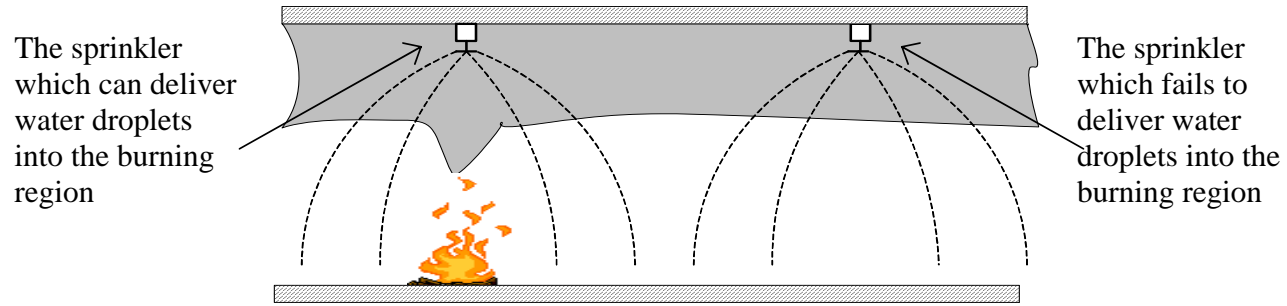

Fig.1. Schematic view of sprinklers' effects on burning region or smoke layer

The droplets motion can be described as the following two equations for the horizontal and vertical velocity components [17]:

$m \frac{d u}{d t}==-\frac{1}{8} \rho_{a} C_{d} \pi \mathrm{d}^{2} \sqrt{u^{2}+v^{2}} u$

$m \frac{d v}{d t}=-\frac{1}{8} \rho_{a} C_{d} \pi \mathrm{d}^{2} \sqrt{u^{2}+v^{2}} v+m g$

where $\rho_{a}$ is the air density, and $C_{d}$ is the drag coefficient reported in the literature [8].

Combining Eq. 3 with Eq. 4, the vertical velocity $v$ can be calculated. $z$ is the distance normal to ceiling, which can be determined by:

$z=\int_{0}^{t} v(t) d t$

The heat balance equation of a single droplet with diameter $d$ can be represented by:

$\frac{4}{3} \pi\left(\frac{d}{2}\right)^{3} \rho_{w} c_{p w} \frac{d T(d)}{d t}=h(d) \pi d^{2}\left(T_{s}-T(d)\right)$ 
where $T(d)$ is the temperature of droplet, $h(d)$ is the convective heat transfer coefficient for each droplet, $T_{s}$ is the temperature of smoke layer.

The convective heat transfer coefficient is calculated by:

$h(d)=\frac{N u(d) \cdot k}{d}$

where $N u(d)$ is the Nusselt number of water droplet. Formula in reference [9] is used to calculate $N u(d), k$ is the thermal conductivity of air.

The boiling temperature of all water droplets is considered to be $373 \mathrm{~K}$. The heat loss of the smoke layer caused by water evaporation is not included in the model. Integrating Eq. 6, the temperature of droplet at the moment when exiting smoke layer, $T(d)_{f}$, can be represented as follows:

$T(d)_{f}-T_{0}=\left[1-\exp \left(-\frac{6 k N u}{\rho_{w} c_{p} d^{2}} t_{f}\right)\right]\left(T_{s}-T_{0}\right) \quad\left(T(d)_{f} \leq 373 K\right)$

The time taken for each droplet to go through the smoke layer, $t_{f}$, is determined by:

$D=\int_{0}^{t_{f}} v(t) d t$

where $D$ is the thickness of smoke layer.

Thus, the heat absorption by a single droplet can be taken as:

$Q_{c}(d)=\frac{4}{3} \pi\left(\frac{d}{2}\right)^{3} \rho_{w} C_{p w}\left(T(d)_{f}-T_{0}\right) N(d)$

Substituting Eq. 8 into Eq. 10, the heat transfer from smoke layer to the whole sprinkler spray can be derived as follows:

$\dot{Q}_{s c}=\left(T_{s}-T_{0}\right) \int_{d 0}^{d \infty} \frac{4}{3} \pi\left(\frac{d}{2}\right)^{3} \rho_{w} c_{p w}\left[1-\exp \left(-\frac{6 k N u}{\rho_{w} c_{p} d^{2}} t_{f}\right)\right] N(d) d(d)$

It is seen from Eq. 11 that the heat transfered from the smoke layer to the sprinkler spray is related to the temperature of smoke layer $T_{s}$ and the droplets exit time $t_{f}$. Considering Eq. $9, t_{f}$ is determined by the smoke layer thickness $D$. Hence $T_{s}$ and $D$ are the primary two independent variables of the model of heat transfer from the smoke layer to sprinkler spray. Since $T_{s}$ and $D$ are unknown and they interact with $Q_{s c}$ during the fire, the model in its present form has limitations for practical application. By combining this model with the fire zone modelling, a relationship between the properties of the smoke layer and the heat transferred to the sprinkler spray is resolved. The governing equations and solution strategy of this new zone model are presented in detail.

\section{MODEL DEVELOPMENT}

\section{Governing equations}

Mass and energy conservation equations for upper smoke layer are included in the fire zone model, which include the cooling effect of sprinkler spray and is termed the Sprinkler Zone Model (SZM). The pressure of the upper and lower layers are assumed to be identical and at ambient pressure. The smoke gas is considered to be an ideal gas. The mass conservation equation for smoke layer is as follows: 
$\frac{d}{d t}\left(\rho_{s} V_{s}\right)=\dot{m}_{p}-\dot{m}_{v}$

where $\dot{m}_{p}$ is the mass accumulation rate flowing across the layer interface, and $\dot{m}_{v}$ is the mass loss rate through the vent.

In the absence of sprinkler spay, the energy equation for smoke layer is similar with that of other zone models such as CFAST6. In the presence of a sprinkler spay, an additional heat loss term $\dot{Q}_{s c}$ is included in the energy conservation equation. A uniform temperature $T_{s}$ is assumed throughout the hot smoke layer by this zone model in both scenarios shown in Fig.1, and is represented as:

$\frac{d}{d t}\left(c_{p s} \rho_{s} V_{s} T_{s}\right)=\dot{Q}_{p}-\dot{Q}_{v}-\dot{Q}_{b c}-\dot{Q}_{r}-\dot{Q}_{s c}$

where $T_{s}$ is the temperature of smoke layer, $c_{p s}$ is the specific heat of smoke, $\dot{Q}_{v}$ is the enthalpy loss rate through vent, $\dot{Q}_{r}$ is the radiative heat transferred from smoke layer to wall boundaries and lower layer, $\dot{Q}_{b c}$ is the convective heat transferred from the smoke layer to the system boundaries, $\dot{Q}_{s c}$ is the heat transfer from the smoke layer to the sprinkler spray, $\dot{Q}_{p}$ is the rate of enthalpy change due to flow across the layer interface, and can be represented as:

$\dot{Q}_{p}=\dot{Q}_{e c}+\dot{Q}_{f}$

where $\dot{Q}_{e c}$ is the enthalpy of air entrained into the plume, and $\dot{Q}_{f}$ is the heat release rate of fire which includes two parts, convective part and radiative part. In this paper, 70 percent of the heat released by fire is assumed to be convective. The other 30 percent is radiative heat which is absorbed by the smoke layer.

\section{Solution strategy}

In addition to heat transfer from the smoke layer to the sprinkler spray, other source terms of the governing equations are solved by a series of sub-models. In order to compare the results of SZM with that of CFAST6, sub-models consistent with CFAST6 are introduced into SZM. McCaffrey's plume model is implemented to calculate mass entrainment rates [18]. Mass flow through vent can be calculated by integrating Bernoulli's equation in the vertical direction, similar to the methodology used with CFAST6 [3]. Convective heat transfer is calculated using the same relationships in CFAST6, which calculates convective heat transfer coefficients of ceiling and walls, respectively [3]. The radiation heat transfer model is based on the work of Siegel and Howell [19], and the two wall exchange algorithm is adopted in this paper. Inner wall temperature and conduction heat through boundaries can be solved by transient one-dimensional conduction model.

The governing equations are iterated with Runge-Kutta method. Heat transfer from the smoke layer to the sprinkler spray is not included in the iterative process prior to sprinkler activation. Following sprinkler activation, a model of heat transfer from smoke layer to sprinkler spray is introduced into the iteration. In the situation that sprinkler droplets fail to reach the fire region, only a model of heat transfer from the smoke layer to the sprinkler spray is accounted for by SZM. However, in the situation where sprinkler droplets have a direct effect upon the fire region, both heat transfer from smoke layer to sprinkler spray and the fire suppression model are implemented in SZM. Fire suppression can be modeled using the algorithm of Evans [20]. Since the thermal response of sprinklers is not included in SZM, it is assumed that sprinklers activate immediately when the smoke layer reaches their activation temperature. The solution procedure of SZM is shown in Fig.2. 


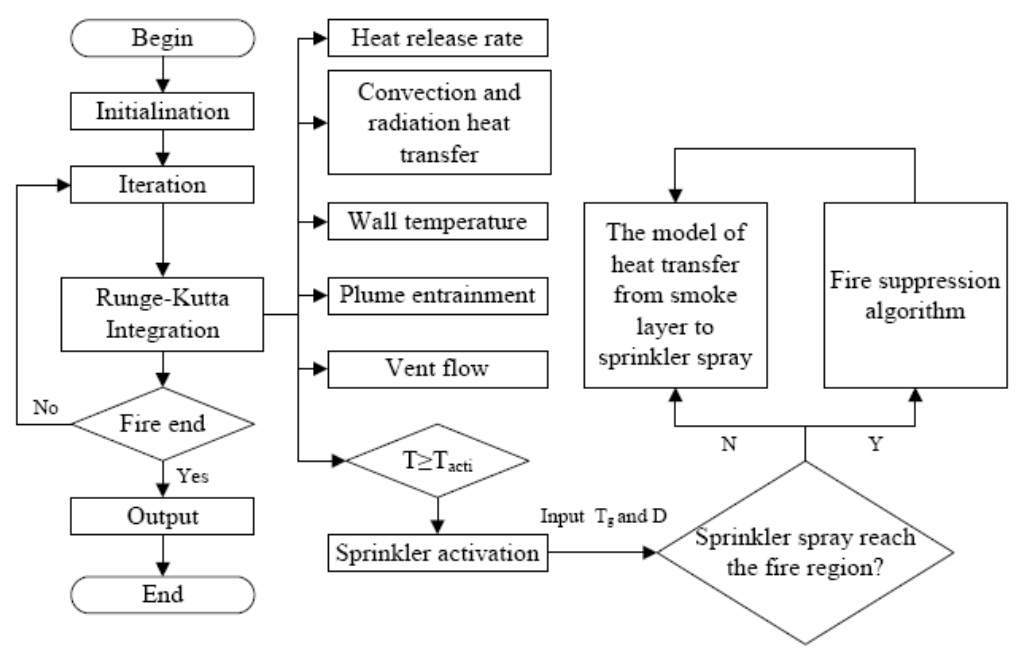

Fig. 2. Solution procedure of SZM

\section{MODEL VALIDATION AND APPLICATION}

\section{Model validation}

Since a number of sub-models and numerical methods are used by SZM, for validation of the SZM's numerical robustness, the temperatures predicted by SZM (without accounting for the heat transfer from smoke layer to sprinkler spray) were compared with that of CFAST6. The geometry, dimensions and heat release rates in both CFAST6 and SZM were similar and compared with data provided by Chung and Dong [22]. It is seen from Fig.3 that up to 150s after the start of the fire, the temperatures of SZM are higher than that of CFAST6. This discrepancy may arise from the fact that the ceiling jet is not accounted for by SZM in this initial period. The temperature of SZM is a little lower than that of CFAST6 after 200s and SZM is unable to calculate the variation of pressure as a single zone model. For this reason, the expansion caused by variation of smoke layer volume can't be estimated by SZM, and this may also be the explanation for the discrepancy between the results of SZM and CFAST6. In general, good agreement is found between the results of SZM and that of CFAST6 when the sprinkler is not activated, indicating that the algorithms and sub-models of SZM are reliable.

Further validation is conducted by comparing the SZM predicted results with experimental data. The test data extracted from Chung and Dong's work [21-22] are used for validation of SZM. Chung and Dong did a series of experiments in a $12 \times 7 \times 3 \mathrm{~m}^{3}$ compartment, for the purpose of measuring the growth of the smoke layer height during the sprinkler activation. The reason for choosing these test data as the benchmarks are as follows: (1) the vertical temperature distributions were measured in the experiments by using four thermocouple trees located at different locations in the test room. (2) The mass loss rates of the fuel were recorded by load cells and thus the transient heat release rates were available [21]. (3) Measurements of the heights of smoke layer were conducted by using light beam detectors. Although the average temperature of smoke layer was not given by Chung and Dong's paper directly, it can be estimated by Eq.15.

$$
T_{e s}=\frac{1}{h} \sum_{i=1}^{n} \Delta h \cdot \frac{1}{4} \sum_{j=1}^{4}\left(\frac{T_{i, j}+T_{i+1, j}}{2}\right)
$$

where $i$ denotes the No. of thermocouple, $j$ is the No. of thermocouple tree, and $n$ is the number of thermocouple within the smoke layer. $\Delta h$ is the height between two neighboring thermocouples, $\mathrm{h}$ is the height of smoke layer which was measured in Chung and Dong' test by light beam detectors. The data of No.1-2 test [22] was used in this paper for comparison. The average temperatures of smoke layer in the No.1-2 test were estimated by Eq.15 and are presented in Fig.3. 


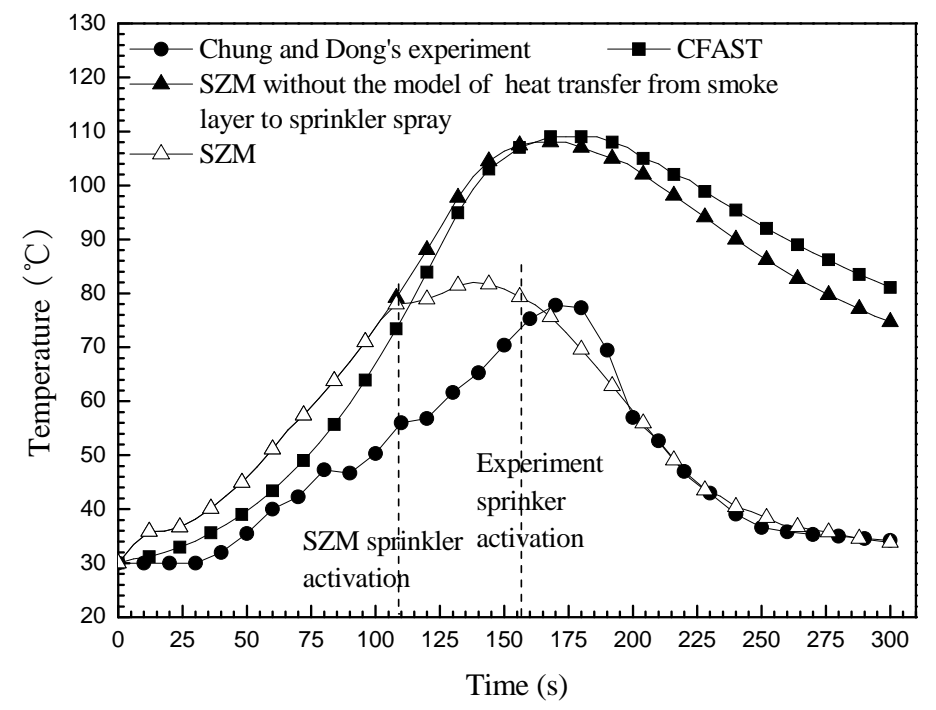

Fig.3. Comparison of smoke layer temperature predicted by SZM, CFAST with experiments

Both the results of SZM with the model of heat transfer from smoke layer to sprinkler spray and that of CFAST6 were compared with the test data, as is illustrated in Fig.3. It is found that CFAST6 overestimates the smoke temperature. Prior to sprinkler activation (which is 169s in the experiment), the predicted temperatures of CFAST are (on average) about 25\% higher than the test data. This overestimation may arise from the intrinsic limitations of zone modeling. Even the large eddy simulation code Fire Dynamics Simulator (FDS) overestimates the growth rates of temperature as reported by Chung and Dong [21]. It is noted that, a larger discrepancy is found between the CFAST6 predictions and the test data after sprinkler activation, the CFAST predicted temperatures are about $86 \%$ higher than the test data on average during the time under sprinkler effects. This larger discrepancy may be attributed to the fact that CFAST model does not account for the effect of cooling the smoke layer by sprinkler spray. The input data of the model of heat transfer from smoke layer to sprinkler spray in SZM are consistent with the sprinkler parameters in Chung and Dong's test. SZM is not capable of predicting the actual activation temperature of sprinkler since the thermal response model of sprinkler and ceiling jet temperature is not included in SZM. To compensate for this limitation, SZM takes the average temperature of smoke layer at the moment when sprinkler activated in the experiment (which is $78^{\circ} \mathrm{C}$ ) as the activation temperature. For this reason, sprinkler activation times predicted by SZM are about 50s earlier than that of the test, as is shown in Fig.3. However, the maximum temperature predicted by SZM agrees well with the test data. Furthermore, the predicted temperatures after 169s (the sprinkler activation time in the experiment) agree quite well with the test data. Taking into account of the cooling effect of sprinkler on smoke layer, SZM predictions were in better agreement with fire experiment data under sprinkler effects.

\section{Case study}

In this section, the fire characteristics of a hypothetical compartment fire were predicted by SZM model. The hypothetical compartment is $5 \mathrm{~m} \times 5 \mathrm{~m}$ in plan and $3.6 \mathrm{~m}$ in height. The door opening is centered on one of the walls, with dimensions $1.2 \mathrm{~m}$ wide and $2 \mathrm{~m}$ high. Two $t^{2}$ fires, with maximum heat release rates of 1054KW (HRR1) and 500KW (HRR2) are used for calculation, both HRR1 and HRR2 have the duration of 600s and the growth coefficient of $0.02635 \mathrm{~kW} / \mathrm{s}^{2}$, and they decays after $400 \mathrm{~s}$ and $462 \mathrm{~s}$, respectively. Three different discharge pressures $(0.05 \mathrm{MPa}, 0.075 \mathrm{MPa}$ and $0.1 \mathrm{MPa}$ ) of sprinkler are adopted in the calculations. Only the situations that the water droplets of sprinkler spray fails to reach the fire region are investigated in this section. The initial ambient temperature is $20^{\circ} \mathrm{C}$, and the water temperature is $19^{\circ} \mathrm{C}$. The input data for SZM are shown in Table 1. 
Table 1. Input data of SZM

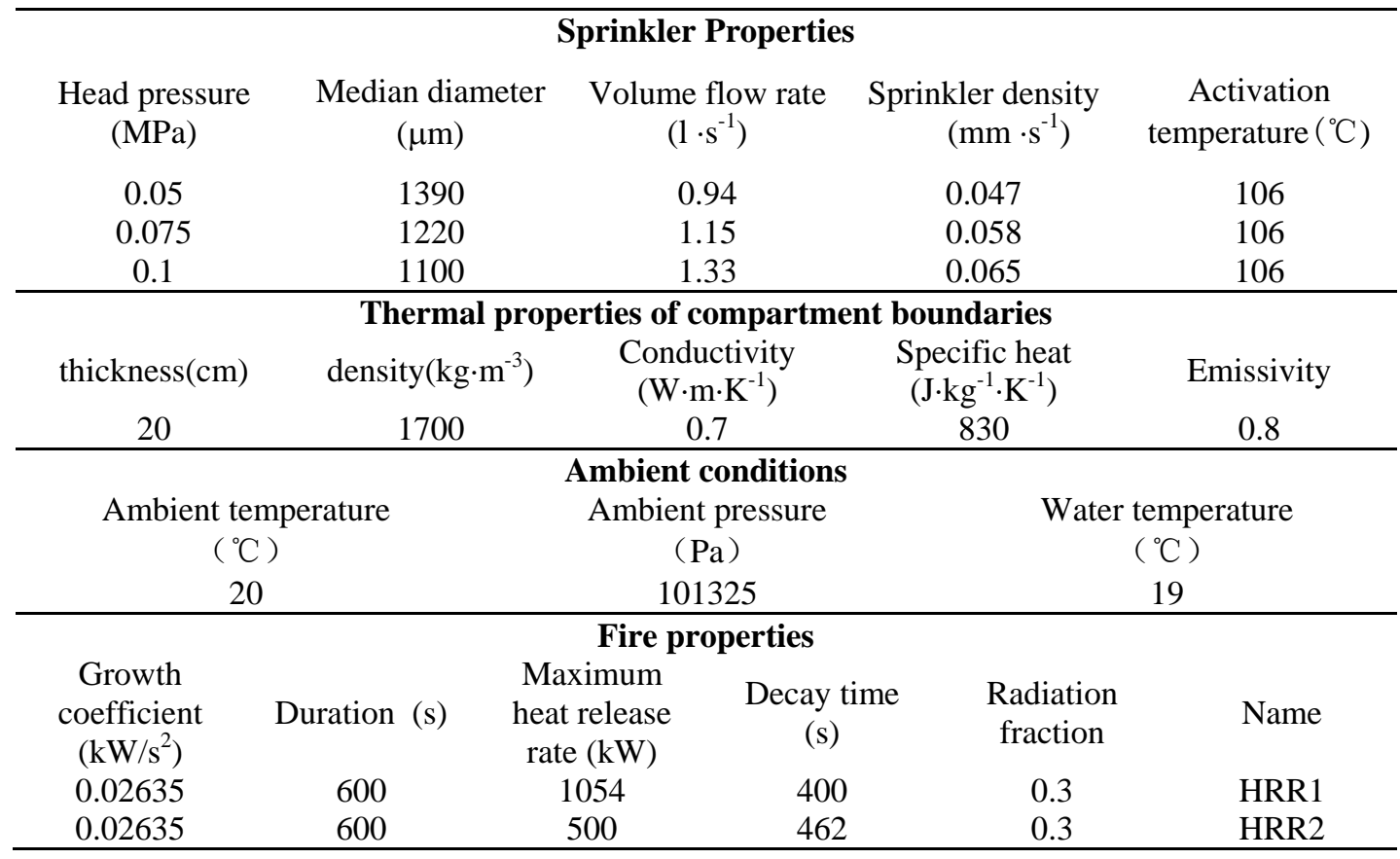

Fig.4 shows the predictions with sprinklers of 0.1MPa operating pressures. A drop of about $156^{\circ} \mathrm{C}$ on average is predicted for HRR1 following sprinkler activation, and $121^{\circ} \mathrm{C}$ on average for HRR2. This indicates that the sprinkler has more marked effect on cooling of the smoke layer under the conditions of higher heat release rates. This may be due to that the heat transferred to sprinkler spray is proportional to the difference between smoke temperature and ambient temperature, as shown in Eq.11. The heat loss sources of smoke layer following sprinkler activation consists of enthalpy losses through the vent flow, convective heat transfer, radiative heat transfer and heat transferred to the sprinkler. Fig. 5 presents the energy balance of the smoke layer for the case of HRR1 and 0.1MPa sprinkler pressure. Table.2 shows the average energy gain rates and average energy loss rates of smoke layer between 200s and 400s. As indicated from Fig. 5 and Table.2, heat loss due to sprinkler spray cooling takes up a higher proportion of heat losses. Therefore, the presence of sprinkler leads to a significant cooling effect on the hot smoke layer.

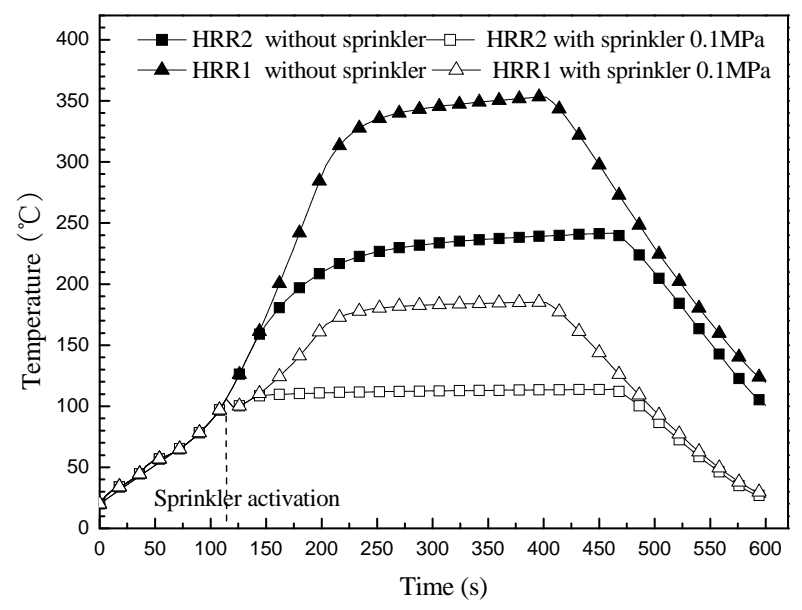

Fig.4. Variation of temperature with and without sprinkler effects 


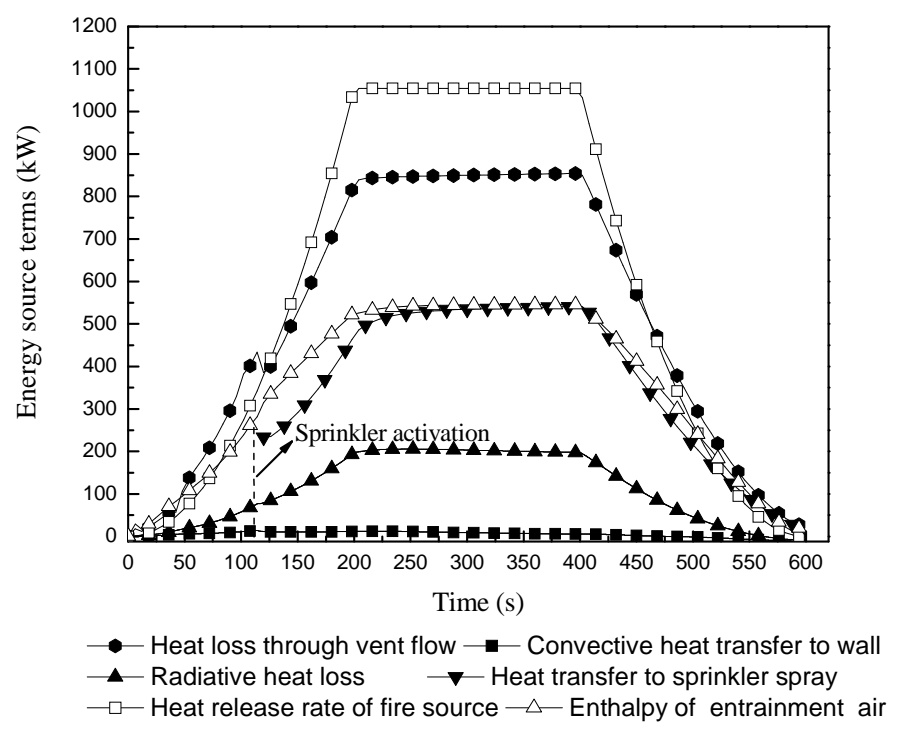

Fig. 5. Variation of heat source terms with sprinkler effects

Table 2. Energy balance of the smoke layer during the steady stage

\begin{tabular}{ccccccccc}
\hline & $\dot{Q}_{b c}$ & $\dot{Q}_{r}$ & $\dot{Q}_{v}$ & $\dot{Q}_{s c}$ & $\begin{array}{c}\text { Total } \\
\text { energy } \\
\text { loss }\end{array}$ & $\dot{Q}_{f}$ & $\dot{Q}_{e c}$ & $\begin{array}{c}\text { Total } \\
\text { energy } \\
\text { gained }\end{array}$ \\
\hline Value(kW) & 9.1 & 202.2 & 849.2 & 529.8 & 1590.3 & 1054 & 542.3 & 1596.3 \\
Proportion & $0.6 \%$ & $12.7 \%$ & $53.4 \%$ & $33.3 \%$ & $/$ & $66.0 \%$ & $34 \%$ & $/$ \\
\hline
\end{tabular}

To ensure adequate capacity for fire suppression, a discharge pressure of $0.1 \mathrm{MPa}$ is mandated by the fire codes of China [23]. In this section, for the purpose of investigating the effect of sprinkler pressure on cooling of the smoke layer, three pressures $(0.05 \mathrm{MPa}, 0.075 \mathrm{MPa}$ and $0.1 \mathrm{MPa})$ were adopted by the SZM, respectively. Fig. 6 shows that there is a relatively small drop of smoke temperature $\left(20^{\circ} \mathrm{C}\right.$ on average) when increasing the discharge pressure from $0.05 \mathrm{MPa}$ to $0.1 \mathrm{MPa}$. In addition to increasing water mass flow rates, a higher sprinkler pressure may also result in a decrease in droplets size and thus potentially provides enhanced cooling due to higher evaporation rates [11]. However, the initial vertical velocities of the droplets are also increased under higher sprinkler pressure, which leads to a reduction in time for droplets passing through the smoke layer. For this reason, only a small drop in temperature was predicted when the discharge pressure varied from $0.05 \mathrm{MPa}$ to $0.1 \mathrm{MPa}$. The sprinkler spray with high discharge velocity may even cause instability in the smoke layer. Therefore, although increasing discharge pressure of sprinklers may suppress fire more effectively, it may not be an effective way to cool the smoke layer, especially for sprinklers which are located away from the fire locus.

In actual fire conditions, the smoke layer within the envelope of sprinkler spray may be thickened due to drag of the water droplets, especially in condition under high sprinkler pressure. However, the drag effect of droplets on smoke layer is not included into this fire zone model and thus the thickness of smoke layer varies little with the sprinkler pressure, as shown in Fig. 6. 


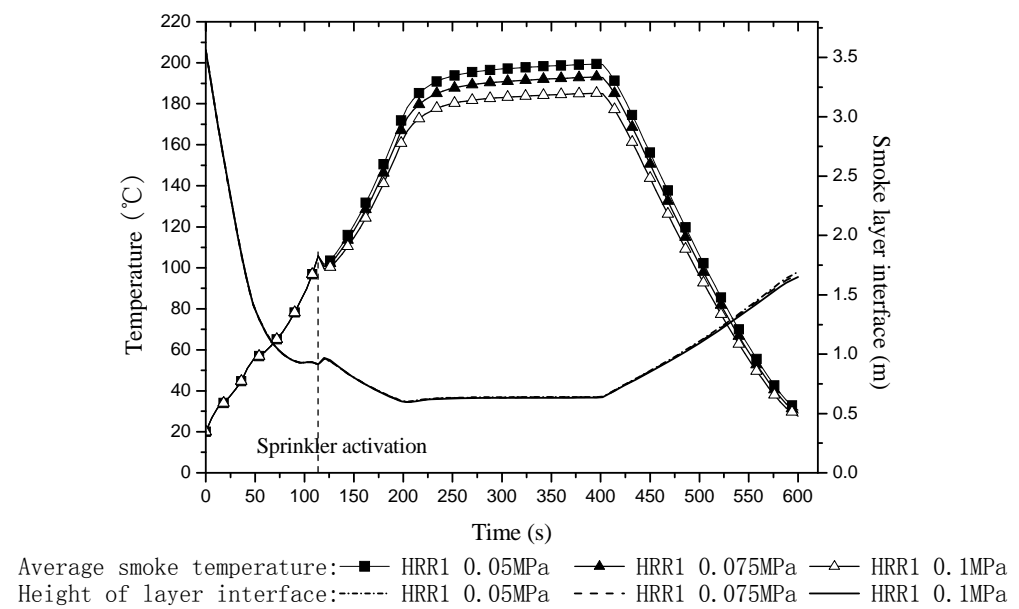

Fig. 6. Variation of smoke layer temperature and interface height with different discharge pressures

\section{CONCLUSIONS}

By considering heat transfer from the smoke layer to the sprinkler spray as an additional term in the energy equation, a fire zone model which includes the cooling effect of sprinklers is developed. This fire zone model has been validated, through comparison with the predictions of the CFAST6 model and the experiment data provided by Chung and Dong. It is shown that the predicted results of this fire zone modeling and CFAST6 are in good agreement prior to sprinkler activation. Following activation of the sprinkler, better agreement can be obtained between the predicted results of the present fire zone model and the experimental data than that of CFAST6. This indicates that accounting for the cooling effect of sprinkler spray on the hot smoke layer is important in fire zone modeling.

A further study has been performed by applying the present fire zone model for the investigation of a hypothetical compartment fire. Two heat release rates of the fire source and three discharge pressures of the sprinkler were examined in this study. Significant decreases in smoke temperatures were predicted following sprinkler activation. A large decrease in temperature resulted under higher heat release rate. Comparing the heat transferred to the sprinkler spray with other heat loss sources of the smoke layer, it is shown that the sprinkler plays an important role in cooling of the hot smoke layer. A relatively small decrease in temperature was predicted by increasing the discharge pressure of sprinkler from $0.05 \mathrm{MPa}$ to $0.1 \mathrm{MPa}$, indicating that increasing discharge pressure may be not an effective way in cooling smoke layer.

However, the smoke layer within envelop of sprinkler spray may become very obscure under the drag effect of sprinkler spray, especially for high sprinkler pressure. This may influence heat transfer between smoke layer and water droplets. The current model has not accounted for the drag effect of droplets on the smoke layer, Li's model [24] correlated the height of smoke layer within sprinkler spray envelop with the drag of water droplets, which will be included into this zone model in the future work.

\section{ACKNOWLEDGEMENT}

This work was supported by the Natural Science Foundation of China (NSFC) under Grant No. 50536030 and the National Key Technology R\&D Program of China under Grant No. 2006BAK06B02.

\section{REFERENCES}

[1] Rasbash, D.J., Rogowski, Z.W., and Stark, S.W.V., (1960) Mechanism of Extinction of Liquid Fires with Water Vessel. Combustion and Flame 4: 223-234. doi:10.1016/S0010-2180(60)80026-0

[2] Rasbash, D.J., (1962) The Extinction of Fires by Water Sprays. Fire Research Abstracts and Reviews 4: 25-53. 
[3] Jones, W.W., et al., “CFAST-Consolidated Model of Fire Growth and Smoke Transport (Version 6)”., National Institute of Standards and Technology Special Publication 1026., Gaithersburg, MD, 2005:59

[4] Cooper, L.Y., (1995) The Interaction of an Isolated Sprinkler Spray and a Two-Layer Compartment Fire Environment. Phenomena and Model Simulations. Fire Safety Journal, 25(2):89-107. doi:10.1016/0379-7112(95)00037-2

[5] Novozhilov, V., (2001) Flashover control under fire suppression conditions. Fire Safety Journal 36: 641-660. doi:10.1016/S0379-7112(01)00019-4

[6] Vaari, J., (2002) A transient one-zone computer model for total flooding water mist fire suppression in ventilated enclosures. Fire Safety Journal 37(3):229-257. doi:10.1016/S0379$\underline{7112(01) 00046-7}$

[7] Morgan, H.P., (1979) Heat transfer From a Buoyant Smoke Layer Beneath a Ceiling to a Sprinkler Spray. 1-A Tentative Theory. Fire and Materials 3(1): 34-38. doi:10.1002/fam.810030107

[8] Chow, W.K., Fong, N.K., (1991) Numerical simulation on cooling of the fire-induced air flow by sprinkler water sprays. Fire Safety Journal 17:263-290. doi:10.1016/0379-7112(91)90023-R

[9] Chow, W.K., Tang, A.C., (1994) Experimental studies on sprinkler water spray--smoke layer interaction. Journal of Applied Fire Science 4(3): 171-184.

[10] Novozhilov, V., Harvie, D.J.E. et al., (1997) A computational fluid dynamics model of fire burning rate and extinction by water sprinkler. Combustion Science and Technology 123:227-245. doi:10.1080/00102209708935629

[11] You, H.Z, Kung, H.C. et al., "Spray cooling in room fires”. NBS-GCR-86-515, National Bureau of Standards, Washiongton, DC,1986.

[12] Beyler, C.L., “The interaction of Fire and Sprinklers”. NBS-GCR-78-121, National Bureau of Standards, Washiongton, DC,1986.

[13] Kung, H.C., (1977) Cooling of room fires by sprinkler spray. ASME Trans J Heat Transfer 99:358

[14] Sheppard, D.T., Spray characteristics of fire sprinklers [D]. Evanston: Northwestern University, 2002

[15] Prahl, J.M., Wendt, B., (1988) Discharge Distribution Performance for an Axisymmetric Model of a Fire Sprinkler Head, Fire Safety Journal 14: 101-111. doi:10.1016/0379-7112(88)90048-3

[16] Chan, T.S., (1994) Measurement of Water Density and Droplet Size Distributions of Selected ESFR Sprinklers. Journal of Fire Protection Engineering 6(2): 79-87. doi:10.1177/104239159400600202

[17] Faeth, G.M., (1983) Evaporation and combustion of sprays. Progress in Energy and Combustion Science 9:1-76. doi:10.1016/0360-1285(83)90005-9

[18] McCaferey, B.J., (1983) Momentum implication for buoyant diffusion flames. Combustion and Flame52:149-167. doi:10.1016/0010-2180(83)90129-3

[19] Siegel, R., Howell, J.R. Thermal radiation heat transfer. 1981, Hemisphere Publishing Corporation, New York, second ed.

[20] Evans, D.D., “Sprinkler fire suppression for HAZARD”. National Institute of Standards and Technology Report NISTIR 5254, Gaithersburg, MD, 1993.

[21] Chung, K.C., Tung, H.S., (2005) A simplified model for smoke filling time calculation with sprinkler effects. Journal of Fire Science 23:279-301. doi:10.1177/0734904105047916

[22] Tung, H.S., Chung, K.C., Study the effect of water suppression on performance-based smoke control design and experimental verification [D]. Yunlin: National Yunlin University of Science and Technology, 2004. 
[23] Code of design for sprinkler systems (GB 50084-2001) [S]. Beijing: China planning press, 2001.

[24] Li, K.Y., Hu, L.H., Huo, R., et al., A mathematical model on interaction of smoke layer with sprinkler spray, Fire Safety Journal (in press) 